\title{
Hybrid palliation for hypoplastic left heart syndrome: Where do we stand now?
}

Paul J. Chai, MD

See related article on pages 182-93.

Hybrid palliation for hypoplastic left heart syndrome and other complex defects remains an option for a subgroup of patients. ${ }^{1,2}$ The hybrid procedure is typically reserved for high-risk patients for whom the risk of the Norwood procedure or potentially the use of cardiopulmonary bypass is believed to be prohibitive. Early enthusiasm for the procedure has matured somewhat over the last few years with many groups now using it only for a specific subset of high-risk patients. ${ }^{3,4}$ This typically includes patients with extreme low birth weight or prematurity, multiorgan dysfunction, or intracerebral bleeds. Overall outcomes remain poor and any advantages related to the delay incurred with a more comprehensive procedure are unknown.

Davies and colleagues ${ }^{6}$ examined the effects of different strategies after hybrid palliation for high-risk patients with hypoplastic left heart syndrome. This is a retrospective review of 37 patients initially treated with the hybrid procedure who then subsequently underwent either a Norwood procedure or a comprehensive stage 2 repair. The authors found that the subsequent management strategy after the hybrid procedure did not affect transplant-free survival through completion of stage 2. Factors associated with mortality included aortic atresia and low birth weight. The authors concluded that the stage 1 Norwood and comprehensive stage 2 procedures are both viable treatment strategies after the hybrid procedure. They also concluded that delaying surgical palliation with a comprehensive stage 2 procedure did not ameliorate the negative impact of early risk factors.

The article has several significant limitations, all of which were noted by the authors. The sample size is limited, which may certainly affect the findings. More importantly, because the subsequent treatment strategies were selected based on the clinical course of the patients, a clear bias

From the Department of Surgery, Columbia University Medical Center, New York, NY.

Disclosures: Author has nothing to disclose with regard to commercial support.

Received for publication Sept 23, 2014; accepted for publication Sept 26, 2014; available ahead of print Oct 25, 2014.

Address for reprints: Paul J. Chai, MD, Morgan Stanley Children's Hospital of New York-Presbyterian, CHN Room 275, 3959 Broadway, New York, NY 10032 (E-mail: pjc2164@cumc.columbia.edu).

J Thorac Cardiovasc Surg 2015;149:194

0022-5223/\$36.00

Copyright (c) 2015 by The American Association for Thoracic Surgery

http://dx.doi.org/10.1016/j.jtcvs.2014.09.112 was introduced into the study. Most patients who underwent the Norwood procedure after hybrid palliation did so because of early failure of the hybrid procedure. Nevertheless, the article represents a real-world scenario in which high-risk patients are initially treated with the hybrid procedure and then treated according to their subsequent progress. The real message in the article may be that important risk factors that are present when treatment strategies are initiated (ie, low birth weight) are not significantly mitigated by initial use of the hybrid procedure. Risk factors are carried throughout the life of the patient.

As experience with the hybrid procedure has matured, many groups have found that the perceived advantages of its use may not be that beneficial and that new risks and complications have been introduced. ${ }^{7}$ The fact that Davies and colleagues ${ }^{7}$ did not find any significant differences in outcome between the use of the Norwood procedure or a comprehensive stage 2 procedure after the hybrid procedure may show more that high-risk infants remain high risk throughout their treatment course and that subsequent treatment strategies do little to mitigate preexisting risk factors. Improving survival in these high-risk infants remains an active area of investigation.

\section{References}

1. Galantowicz M, Cheatham JP, Phillips A, Cua CL, Hoffman TM, Hill SL, et al. Hybrid approach for hypoplastic left heart syndrome: intermediate results after the learning curve. Ann Thorac Surg. 2008;85:2063-70; discussion 2070-71.

2. Bacha EA, Daves S, Hardin J, Abdulla RI, Anderson J, Kahana M, et al. Singleventricle palliation for high-risk neonates: the emergence of an alternative hybrid stage I strategy. J Thorac Cardiovasc Surg. 2006;131:163-71.e2.

3. Russell RA, Ghanayem NS, Mitchell ME, Woods RK, Tweddell JS. Bilateral pulmonary artery banding as rescue intervention in high-risk neonates. Ann Thorac Surg. 2013;96:885-90.

4. Guleserian KJ, Barker GM, Sharma MS, Macaluso J, Huang R, Nugent AW, et al. Bilateral pulmonary artery banding for resuscitation in high-risk, single-ventricle neonates and infants: a single-center experience. J Thorac Cardiovasc Surg. 2013; 145:206-13; discussion 213-14.

5. Hickey EJ, Nosikova Y, Zhang H, Caldarone CA, Benson L, Redington A, et al. Very low-birth-weight infants with congenital cardiac lesions: is there merit in delaying intervention to permit growth and maturation? J Thorac Cardiovasc Surg. 2012;143:126-36. 136.e1.

6. Davies RR, Radtke W, Bhat MA, Baffa JM, Woodford E, Pizarro C. Hybrid palliation for critical systemic outflow obstruction: Neither rapid stage 1 Norwood nor comprehensive stage 2 mitigate consequences of early risk factors. J Thorac Cardiovasc Surg. 2015;149:182-93.

7. Stoica SC, Philips AB, Egan M, Rodeman R, Chisolm J, Hill S, et al. The retrograde aortic arch in the hybrid approach to hypoplastic left heart syndrome. Ann Thorac Surg. 2009;88:1939-46; discussion 1946-7. 